\title{
Improving hemoglobin estimation accuracy through standardizing of light-emitting diode power
}

\author{
Caje Francis Pinto, Jivan Shrikrishna Parab, Marlon Darius Sequeira, Gourish Naik \\ Electronics Program, School of Physical and Applied Sciences, Goa University, Goa, India
}

\begin{tabular}{l}
\hline \hline Article Info \\
\hline Article history: \\
Received Jan 4, 2021 \\
Revised Jul 16, 2021 \\
Accepted Aug 1, 2021 \\
\hline
\end{tabular}

Keywords:

Anemia

Bland-Altman

Embedded

Hemoglobin

Photoplethysmography

Standardization

\begin{abstract}
Nowadays, hemoglobin monitoring is essential during surgeries, blood donations, and dialysis. Which are normally done using invasive methods. To monitor hemoglobin, a non-invasive hemoglobin meter was developed with five fixed light-emitting diode (LED) wavelengths at $670 \mathrm{~nm}, 770 \mathrm{~nm}$, $810 \mathrm{~nm}, 850 \mathrm{~nm}, 950 \mathrm{~nm}$ and controlled using an Arduino Uno embedded development board. A photodetector with an on-chip trans-impedance amplifier was utilized to acquire the transmitted signal through the finger using the photoplethysmography (PPG) principle. Before the standardization of LED power, we had tested the designed system on fifteen subjects for the five wavelengths and estimated the hemoglobin with an accuracy of $96.51 \%$ and root mean square error (RMSE) of $0.57 \mathrm{gm} / \mathrm{dL}$. To further improve the accuracy, the LED power was standardized and the PPG signal was reacquired on the same subjects. With this, the accuracy improved to $98.29 \%$ and also reduced the RMSE to $0.36 \mathrm{gm} / \mathrm{dL}$. The designed system with LED power standardization showed a good agreement with pathology results with the coefficient of determination $\mathrm{R}^{2}=0.981$. Also, Bland-Altman analysis was used to evaluate the designed system and it showed good agreement between the two measurements.
\end{abstract}

This is an open access article under the CC BY-SA license.

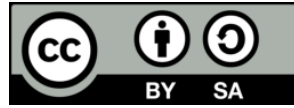

\section{Corresponding Author:}

Jivan Shrikrishna Parab

Electronics Program, School of Physical and Applied Sciences, Goa University

Taleigao, Goa, India

Email: jsparab@unigoa.ac.in

\section{INTRODUCTION}

Hemoglobin is a protein that is found in human blood that carries oxygen from the lungs to different parts of the body. The normal range of Hemoglobin concentration in blood is from 13.5 to $17 \mathrm{gm} / \mathrm{dL}$ for males and 12 to $15 \mathrm{gm} / \mathrm{dL}$ for females [1]. Anemia is a serious public health problem affecting $25 \%$ of the world's population consisting mostly of women and children below 5 years old [2]. Anemia is a disorder in which the blood lacks the necessary amount of healthy red blood cells [3]. Women who are anemic have severe problems during menstruation and pregnancy. Pregnant women who are anemic have a higher risk of giving birth to babies that are underweight, as well as a higher risk of prenatal and maternal death [4]-[9]. Hemoglobin testing is a crucial test for determining anemia in subjects donating blood and in patients awaiting surgical procedures [10]-[12]. The prevalence of Anemia in all the groups in India and all over the world are shown in Table 1.

In the invasive method, blood is drawn from the arm using a syringe. This technique is very painful, time-consuming, and not in real-time. A non-invasive technique enables for one-time or continuous hemoglobin monitoring with minimal risk of infection and discomfort. Several researchers have worked on developing non-invasive hemoglobin meters and some are still working to improve the accuracy of estimating non- invasive hemoglobin. Timm et al. [13], designed a system with three light-emitting diode (LED) wavelengths to estimate the concentration of hemoglobin using the photoplethysmography (PPG) principle and 
a blood gas analyzer was used for system calibration. Doshi and Panditrao [14] developed a device for hemoglobin determination by calculating the amount of light absorption by oxy and deoxy hemoglobin at two different wavelengths $(660 \mathrm{~nm}$ and $940 \mathrm{~nm})$. Azarnoosh and Doostdar [15], recorded PPG signal simultaneously at four different wavelengths $(560 \mathrm{~nm}, 590 \mathrm{~nm}, 660 \mathrm{~nm}$ and $950 \mathrm{~nm})$. It showed a high correlation between PPG signal characteristics and hemoglobin concentration. Pinto et al. [16], designed a system with five LEDs in the wavelength range of $670 \mathrm{~nm}$ to $950 \mathrm{~nm}$ and a single photo detector to capture the PPG signal and the results showed better accuracy of estimating total hemoglobin. Yi et al. [17], created a noninvasive hemoglobin apparatus with eight different laser diodes in the wavelengths range of $600 \mathrm{~nm}$ to 1100 $\mathrm{nm}$ to acquire PPG signals. There are also several commercially available non-invasive hemoglobin estimation instruments with diagnostic accuracy of less than $1 \mathrm{gm} / \mathrm{dl}$. Radical 7, a non-invasive meter developed by Masimo Corporation, measures hemoglobin content based on light absorption in the blood utilizing different LED [18]. The NBM 200 is another non-invasive hemoglobin meter that works on occlusion spectroscopy and calculates the intensity of multiwave length light passing through the finger while blood flow is briefly occluded [19]. These devices are very expensive and not affordable to common people.

In this paper a low-cost real-time embedded system with Arduino Uno was developed to estimate hemoglobin concentration non-invasively with five LED wavelengths. The main objectives are to designing a system with five standardized LEDs and a photodetector for recording the PPG signal. To implement an algorithm to remove the variations in the PPG signal and to extract the PPG features of the PPG signal. And to estimate non-invasive total hemoglobin concentration with high accuracy.

Table 1. Statistics of anemia by world health organization [20]

\begin{tabular}{ccc}
\hline Prevalence of Anemia & World & India \\
\hline Non-Pregnant women (\%) & 29.6 & 53.1 \\
Pregnant women (\%) & 36.5 & 50.1 \\
Children less than 5 years (\%) & 39.8 & 53.4 \\
\hline
\end{tabular}

\section{RESEARCH METHOD}

In our designed system, total hemoglobin was estimated by standardizing all five LEDs power. From the literature [21], [22], it was observed that oxy-hemoglobin and reduced hemoglobin exhibit a significant difference in the molar extinction coefficient as shown in Figure 1. Since near-infrared light penetrates tissues with greater depth and therefore wavelengths from $600 \mathrm{~nm}$ to $1000 \mathrm{~nm}$ are used as LED sources for noninvasive hemoglobin estimation [23]. The intensities of all these LEDs are different. Before they can be compared, the measured light intensities at various wavelengths must first be standardized. For different wavelengths, the tissue's absorbing properties and the sensitivity of the photodetector also differs [24], [25].

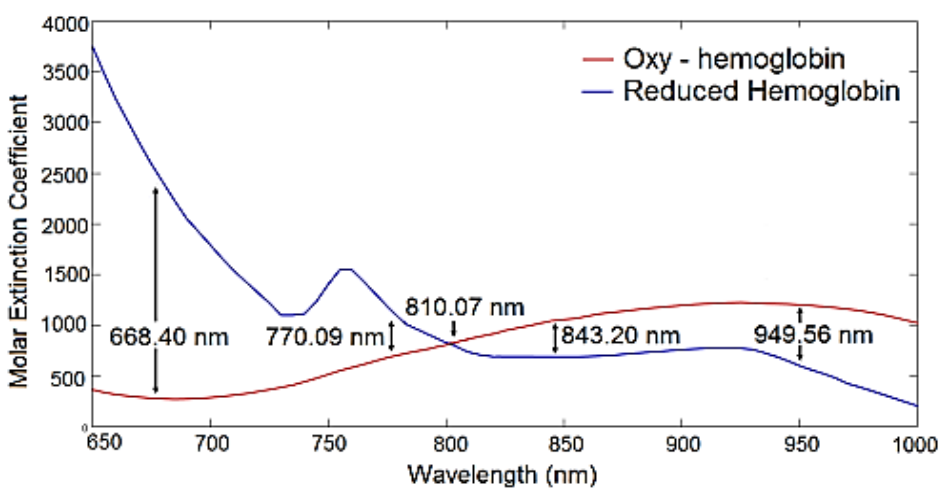

Figure 1. Molar extinction coefficients vs measured wavelengths of multichip LEDs

\subsection{Process of LED standardization}

The first step of standardization is to verify the wavelengths of the multichip LEDs. These wavelengths are verified using (a) Ocean Optics USB 2000+ Spectrometer for the wavelengths from 670 to $850 \mathrm{~nm}$ and NIRQuest spectrometer for $950 \mathrm{~nm}$. During the verification process, the multichip LEDs were placed in front of the spectrometer detector and the peak wavelength of the LEDs was observed on the Ocean Optics SpectraSuite as shown in Figure 2. This entire experiment was carried out in the darkroom. 


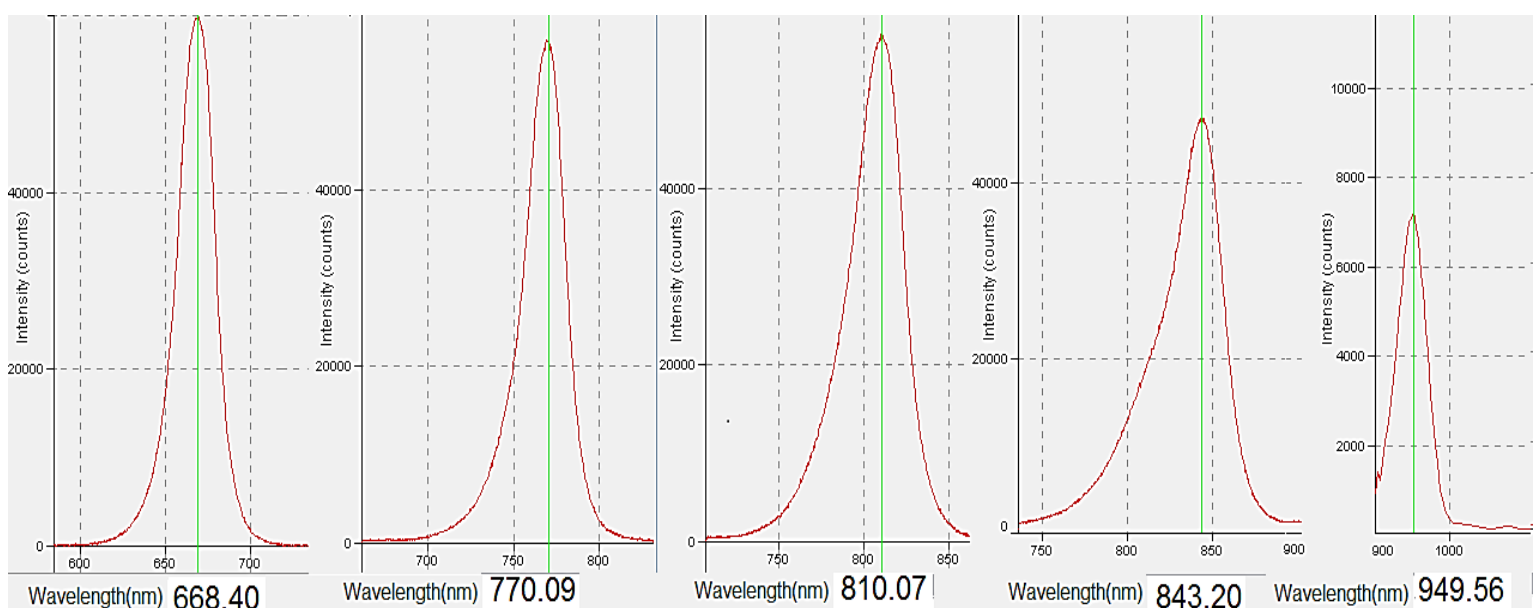

Figure 2. Peak wavelength of the multichip LEDs

The second step involved in standardization is power measurement of individual LEDs (MTMD6788594SMT6) which was done using Newport power meter 2936R with a silicon detector at a fixed distance of $1.2 \mathrm{~cm}$. Initially, we had used some random fixed value of resistance that is $68 \Omega$ and the power of the individual LEDs was measured without standardization. These are listed in Table 2 and it was observed that the power of the individual LED's differs. When we recorded the PPG signal with these LEDs, we had to apply a calibration factor in the software algorithm which was resulting in a slight error in the estimation of hemoglobin.

Table 2. Without standardized LEDs power

\begin{tabular}{cc}
\hline Wavelength of LED $(\mathrm{nm})$ & LEDs power Observed $(\mathrm{mW})$ \\
\hline 670 & 1.02 \\
770 & 1.16 \\
810 & 1.05 \\
850 & 1.04 \\
950 & 1.49 \\
\hline
\end{tabular}

Later, the LED power was standardized by maintaining constant power of $1 \mathrm{~mW}$ for the individual LEDs using the Newport power meter. To do that we had to adjust the forward current flowing through the LEDs by varying the limiting resistance. A fixed resistance value was introduced for each individual LED to maintain constant radiant LED power of $1 \mathrm{~mW}$. Also, the forward current (in $\mathrm{mA}$ ) flowing through LEDs and voltage drop of each LED were measured using the multimeter. The following resistors were selected to obtain constant power are listed in Table 3.

Table 3. Standardized LEDs power

\begin{tabular}{cccc}
\hline $\begin{array}{c}\text { Wavelength of } \\
\text { LEDs }(\mathrm{nm})\end{array}$ & $\begin{array}{c}\text { Current flowing through } \\
\text { the LED }(\mathrm{I}(\mathrm{mA}))\end{array}$ & $\begin{array}{c}\text { Voltage Drop across } \\
\text { LED }\left(\mathrm{V}_{\mathrm{D}}\right)\end{array}$ & $\begin{array}{c}\text { Limiting } \\
\text { Resistance }(\Omega)\end{array}$ \\
\hline 670 & 21.1 & 1.80 & 71 \\
770 & 18.3 & 1.62 & 92 \\
810 & 23.4 & 1.55 & 75 \\
850 & 24.7 & 1.46 & 74 \\
950 & 12.3 & 1.23 & 168 \\
\hline
\end{tabular}

The limiting resistance for the individual LEDs is calculated using

$$
R=\frac{V_{S}-V_{D}}{I}
$$

where $\mathrm{V}_{\mathrm{S}}$ is the supply voltage i.e. $3.3 \mathrm{v}$ and $\mathrm{V}_{\mathrm{D}}$ is the voltage drop of the LED, $\mathrm{I}$ is forward current in $\mathrm{mA}$. The circuit diagram for standardizing LED power is shown in Figure 3. 

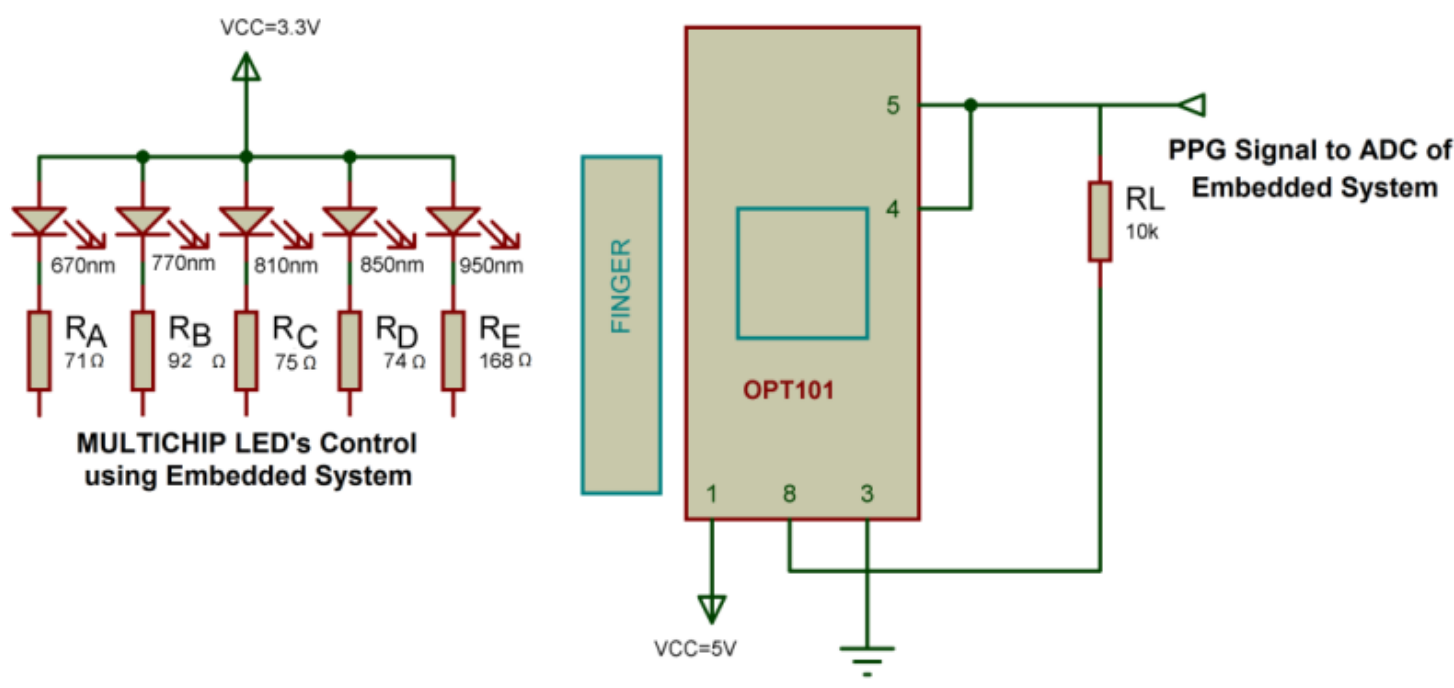

Figure 3. Circuit diagram of multichip LEDs with constant power output with OPT101

\subsection{System design}

The system design of the Non-invasive hemoglobin meter is shown in Figure 4. A system was designed with five LEDs on a multichip (MTMD6788594SMT6) with a photodetector OPT101. The five LEDs were turned on in sequential order using the Arduino Uno embedded development board.

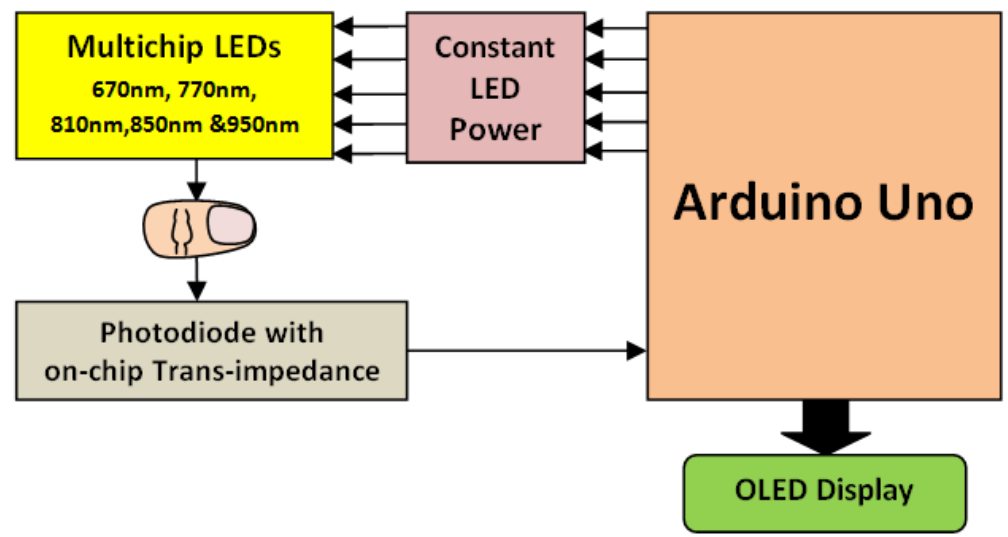

Figure 4. Block diagram of the system designed

Each LED is trans-illuminated on a small area of skin on the fingertip. Due to the cardiac cycle, the blood volume varies in the arteries and therefore there is variation in light intensity through the fingertip. This variations in the light intensity are detected by the OPT101 which is converted into voltage called as PPG signal. This signal is then digitized using the Arduino Uno system's 10-bit ADC. These digitized data are then processed to estimate and display total hemoglobin on the organic light emitting diode (OLED).

\subsection{Computing total hemoglobin from PPG signal}

The principal light absorbers in the area of interest are the arterial and venous blood, skin pigmentation [26]. The PPG signal is a pulsating waveform that contains both alternating current (AC) and direct current (DC) components. The pulsating AC component arises from the variation of blood volume during the systolic and diastolic states. The DC component occurs due to attenuation by the epidermis, skin, tissue. During the systolic cycle, the volume of blood increases due to the increase in the arterial diameter. As a result, the absorbance of light in tissues containing arteries increases. During the diastolic cycle, the reverse occurs. This results in a time-varying transmitted light signal which is called a photoplethysmography signal [27], [28]. 


$$
A_{\lambda}=\log \left[\frac{A C \text { Component of the } P P G}{D C \text { Component of the } P P G}\right]
$$

Where $A_{\lambda}$ is optical density. Using (2), the optical density for the five PPG wavelengths is calculated. The AC component of a PPG signal is the difference between its Peak (maximum) and Valley (minimum) voltages, whereas the DC component is the Valley voltage.

$$
\left[\begin{array}{c}
H b \\
H b O_{2}
\end{array}\right]=\left[\begin{array}{l}
A_{670} \\
A_{770} \\
A_{810} \\
A_{850} \\
A_{950}
\end{array}\right] *\left[\begin{array}{l}
\varepsilon H b^{670} \varepsilon H b O_{2}^{670} \\
\varepsilon H b^{770} \varepsilon H b O_{2}^{770} \\
\varepsilon H b^{810} \varepsilon H b O_{2}^{810} \\
\varepsilon H b^{850} \varepsilon H b O_{2}^{850} \\
\varepsilon H b^{950} \varepsilon H b O_{2}^{950}
\end{array}\right]^{-1}
$$

Where:

$\varepsilon \mathrm{Hb}^{\lambda} \rightarrow$ molar extinction coefficient for reduced hemoglobin for a specific wavelength.

$\varepsilon \mathrm{HbO}_{2}^{\lambda} \rightarrow$ molar extinction coefficient for oxy-hemoglobin for a specific wavelength.

$\mathrm{Hb} \& \mathrm{HbO}_{2} \rightarrow$ concentration of oxy-hemoglobin and reduced hemoglobin in grams per liter [29].

Total hemoglobin is estimated by calculating the concentration of oxy-hemoglobin and reduced hemoglobin using (3). The entire flow of the system for estimating the total hemoglobin non-invasively is depicted in Figure 5. First, the OLED is configured to display the contents. The PPG signal is recorded for five different LED wavelengths. A moving average filter is used to remove the variations in the PPG signal. The peak voltage and valley voltage of the PPG signal is extracted for each PPG signal. Quality assessment is done for each PPG signal to obtain the good peaks and valleys. Here, the mean of peaks and the mean of valley voltage of the PPG are calculated. If the peak and valley voltage is closer to the mean peak and mean valley, those values are saved; else, they are discarded in the computation. The AC component and DC component for each PPG wavelength are calculated. Next, each PPG signal's optical density is calculated. Next, the subject's total hemoglobin is estimated using the optical density and extinction coefficients of hemoglobin at five different wavelengths. Finally, the designed system with five wavelengths (non-invasive method) displays the total hemoglobin level on the OLED display. The entire design of the hemoglobin meter is shown in Figure 6.

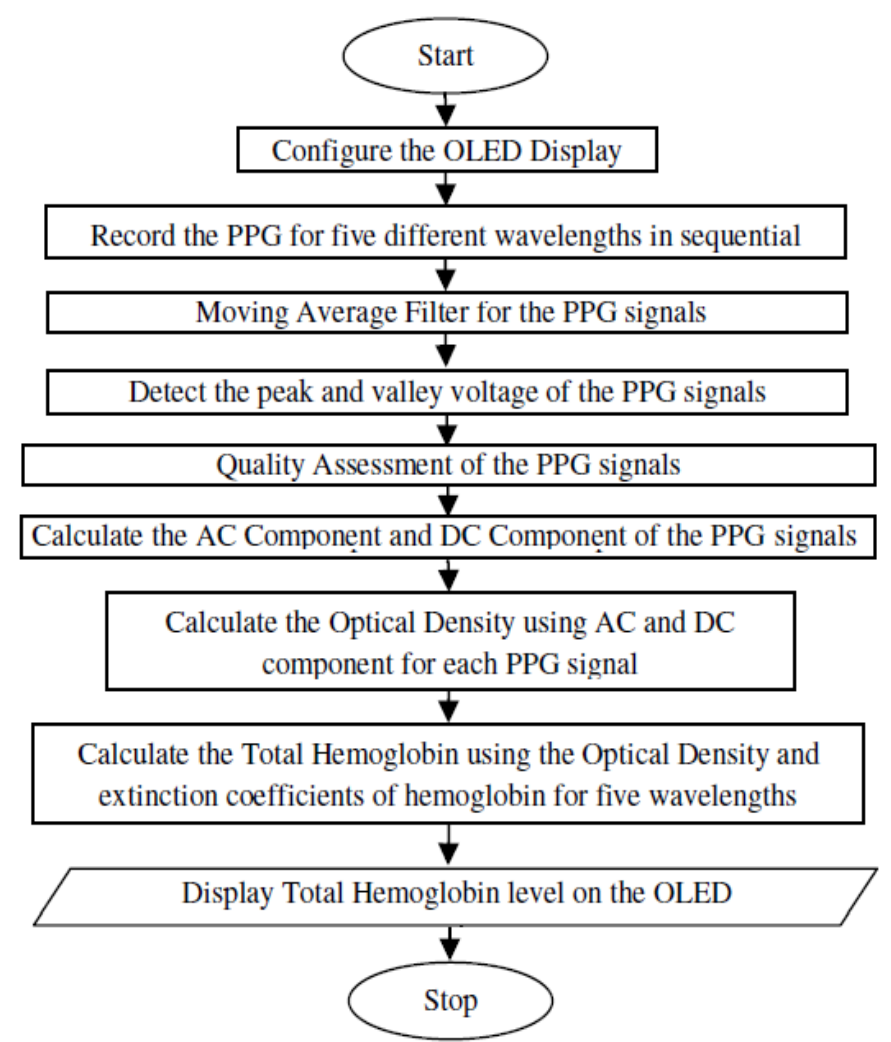

Figure 5. The entire flow of the implemented system 


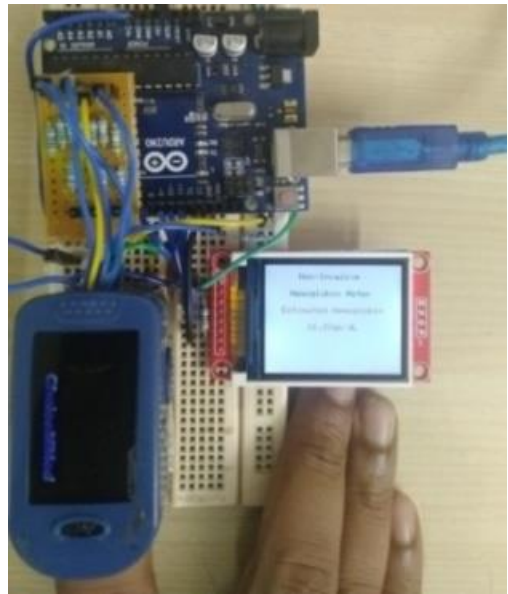

Figure 6. Designed hemoglobin measurement system

\section{RESULTS AND DISCUSSION}

The non-invasive system for hemoglobin estimation with five wavelengths with $1 \mathrm{~mW}$ radiant power and exposure duration of less than 30 seconds. In this study, the subjects were fifteen individuals (Ten males and five females) between the age group of 18 to 60 years. Initially, total hemoglobin was estimated without standardization of LED power. The PPG signals were recorded at five different wavelengths. Later, total hemoglobin was estimated using standardized LED power on the same subjects. The invasive measurement was also conducted with the same subject at the same time in the pathology laboratory to confirm the estimated result obtained from our system. Each individual LED was turned ON in a sequential order for five seconds for recording each PPG signal with a one-second delay between each recording as shown in Figure 7.
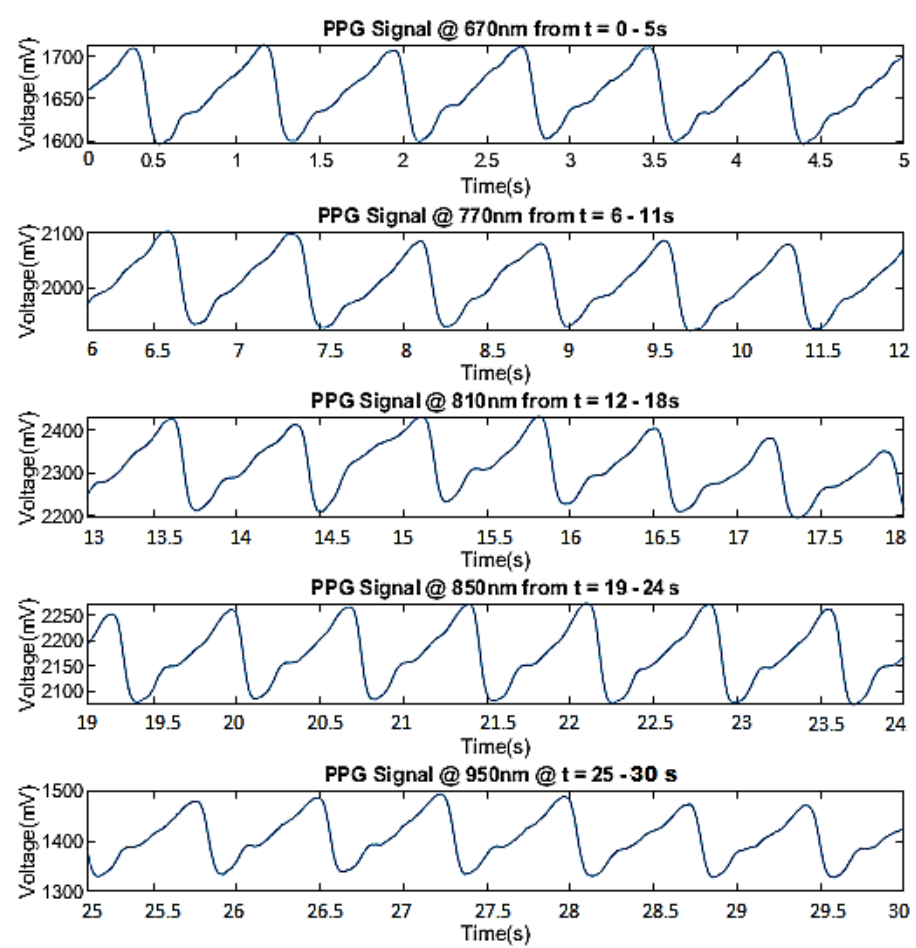

Figure 7. PPG signal for different wavelengths with standardization of LED power

Table 4 indicates the estimation of total hemoglobin for five wavelengths without and with standardized LEDs power. The root mean square error (RMSE) between the reference values and estimated 
hemoglobin without standardization of LED power was $0.59 \mathrm{gm} / \mathrm{dL}$ and with standardization of LED power was $0.32 \mathrm{gm} / \mathrm{dL}$. The accuracy for hemoglobin estimation without standardization of LED power was $96.51 \%$ and the accuracy for estimating total hemoglobin with standardization of LED power was improved to $98.29 \%$.

Table 4. Hemoglobin estimation for subjects

\begin{tabular}{|c|c|c|c|c|c|}
\hline \multirow[b]{2}{*}{ Subject No } & \multirow{2}{*}{$\begin{array}{l}\text { Total Hemoglobin } \\
\text { measured in Pathology } \\
\text { Laboratory } \\
(\mathrm{gm} / \mathrm{dL})\end{array}$} & \multicolumn{2}{|c|}{$\begin{array}{c}\text { Total Hemoglobin estimated with the } \\
\text { designed system (Non-invasive } \\
\text { method) }\end{array}$} & \multicolumn{2}{|c|}{$\begin{array}{c}\text { Error in Total Hemoglobin } \\
\text { measured }\end{array}$} \\
\hline & & $\begin{array}{l}\text { Without } \\
\text { Standardized } \\
\text { LEDs power } \\
(\mathrm{gm} / \mathrm{dL})\end{array}$ & $\begin{array}{l}\text { With } \\
\text { Standardized } \\
\text { LEDs power } \\
(\mathrm{gm} / \mathrm{dL})\end{array}$ & $\begin{array}{l}\text { Without } \\
\text { Standardized } \\
\text { LEDs power } \\
(\mathrm{gm} / \mathrm{dL})\end{array}$ & $\begin{array}{c}\text { With } \\
\text { Standardized } \\
\text { LEDs power } \\
\text { (gm/dL) }\end{array}$ \\
\hline Sub. 1 & 17.50 & 16.87 & 17.02 & 0.63 & 0.48 \\
\hline Sub. 2 & 15.50 & 13.96 & 14.74 & 1.54 & 0.76 \\
\hline Sub. 3 & 11.20 & 11.52 & 11.37 & 0.32 & 0.17 \\
\hline Sub. 4 & 16.20 & 15.92 & 16.34 & 0.28 & 0.14 \\
\hline Sub. 5 & 14.00 & 13.65 & 13.98 & 0.35 & 0.02 \\
\hline Sub. 6 & 12.50 & 11.80 & 12.97 & 0.70 & 0.47 \\
\hline Sub. 7 & 15.20 & 14.82 & 15.09 & 0.38 & 0.11 \\
\hline Sub. 8 & 13.50 & 12.97 & 13.11 & 0.53 & 0.39 \\
\hline Sub. 9 & 16.70 & 16.46 & 16.60 & 0.24 & 0.10 \\
\hline Sub. 10 & 12.20 & 11.89 & 12.07 & 0.31 & 0.13 \\
\hline Sub. 11 & 14.90 & 14.39 & 14.69 & 0.51 & 0.21 \\
\hline Sub. 12 & 16.70 & 16.15 & 16.45 & 0.55 & 0.25 \\
\hline Sub. 13 & 14.50 & 14.04 & 14.29 & 0.46 & 0.21 \\
\hline Sub. 14 & 16.80 & 16.36 & 16.54 & 0.44 & 0.26 \\
\hline Sub. 15 & 12.00 & 11.62 & 11.94 & 0.38 & 0.06 \\
\hline
\end{tabular}

\subsection{Regression analysis}

Figure 8 provides a comparison of estimated hemoglobin using the designed system (non-invasive method) vs measured hemoglobin using invasive method for fifteen subjects. The regression analysis gives a coefficient of determination $\left(\mathrm{R}^{2}\right)$ of 0.965 for estimating total hemoglobin without standardization of LED power and $\left(\mathrm{R}^{2}\right)$ of 0.981 with standardization of LED power and shows a better fit for the model.

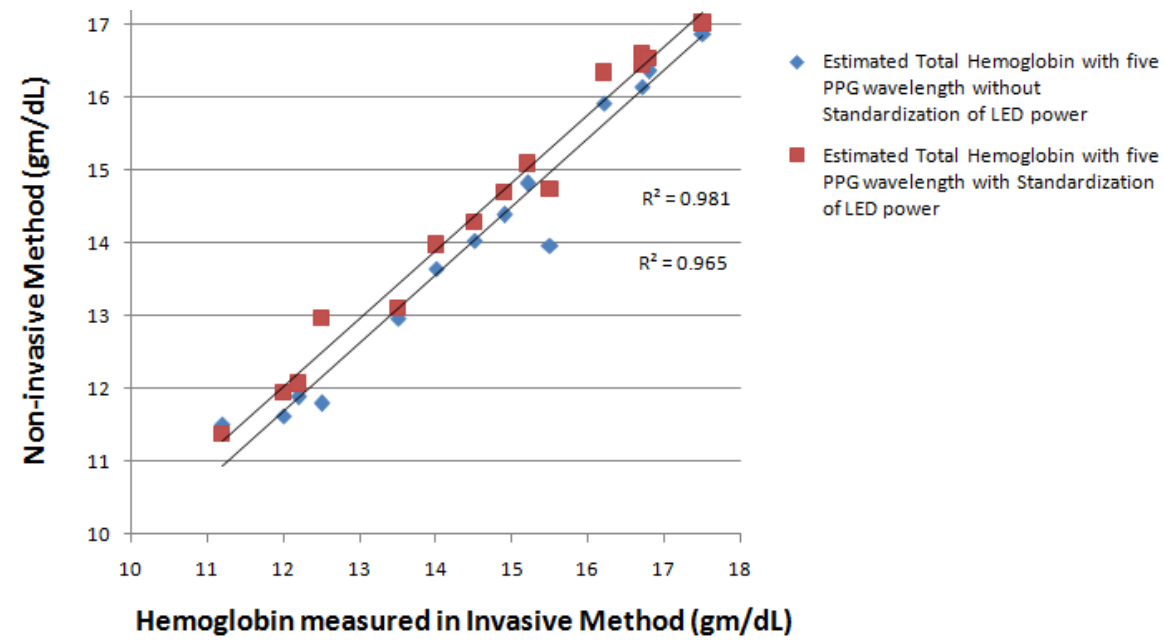

Figure 8. Estimated hemoglobin with the designed system (non-invasive) vs measured hemoglobin (invasive)

\subsection{Bland-Altman analysis} [30].

The Bland-Altman analysis compares the estimated and reference measurement values graphically

$$
\operatorname{Bias}(\overline{\mathrm{d}})=\frac{1}{\mathrm{n}} \sum_{\mathrm{a}=1}^{\mathrm{n}} \mathrm{d}_{\mathrm{a}}
$$

Where $d_{a}$ : reference value-estimated value, $n$ : the number of subjects. 
Standard deviation $\left(\mathrm{S}_{\mathrm{d}}\right)=\sqrt{\frac{1}{\mathrm{n}-1} \sum_{\mathrm{a}=1}^{\mathrm{n}}\left(\mathrm{d}_{\mathrm{a}}-\overline{\mathrm{d}}\right)^{2}}$

limits of agreement $=$ Bias $\pm 1.96 \mathrm{~S}_{\mathrm{d}}$

Figure 9 shows the Bland-Altman analysis for estimating hemoglobin. The limits of agreements and bias are indicated by the outer dotted lines and a black middle line respectively. The bias, standard deviation, and levels of agreement are calculated by using (4), (5), and (6) respectively. From Figure 9, Bias is $0.47 \mathrm{gm} / \mathrm{dL}, S_{\mathrm{d}}$ of $0.38 \mathrm{gm} / \mathrm{dL}$, and limits of agreement from 1.2 to $-0.28 \mathrm{gm} / \mathrm{dL}$ for total hemoglobin estimation without standardization of LED's power. Similarly, with standardized LED power, the bias, $\mathrm{S}_{\mathrm{d}}$ and limits of agreement are $0.15 \mathrm{gm} / \mathrm{dL}, 0.29 \mathrm{gm} / \mathrm{dL}$ and 0.71 to $-0.42 \mathrm{gm} / \mathrm{dL}$ respectively. The values plotted showed less spread across the bias for the five wavelengths PPG after standardization of LED power.
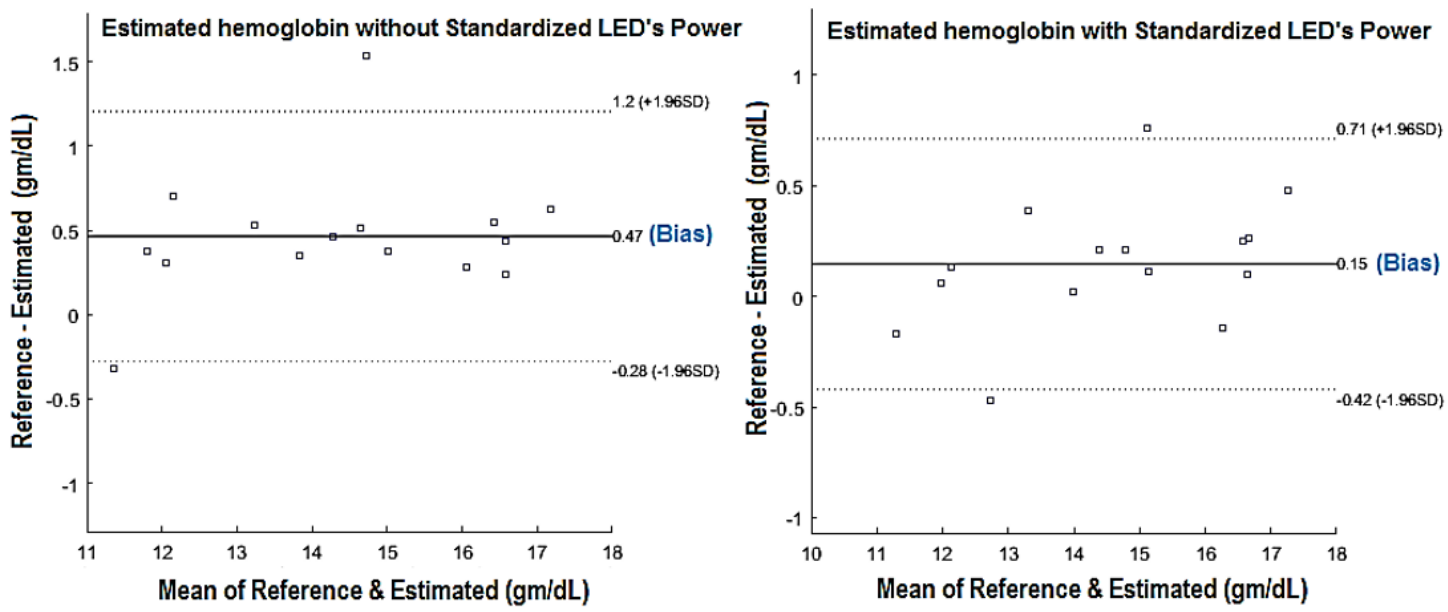

Figure 9. Bland-Altman analysis for the designed system

\section{CONCLUSION}

Accurate non-invasive estimation of total hemoglobin is of utmost importance. Here we report a newly-developed non-invasive hemoglobin monitoring system with five fixed LED wavelengths at $670 \mathrm{~nm}$, $770 \mathrm{~nm}, 810 \mathrm{~nm}, 850 \mathrm{~nm}$, and $950 \mathrm{~nm}$ with standardized LED power. The monitoring system has been tested on fifteen subjects without and with standardization of LED power. The results of both measurements were compared to those obtained at a pathology lab utilizing invasive methods. The accuracy of estimating total hemoglobin was improved from $96.51 \%$ to $98.29 \%$ and the RMSE was reduced from $0.57 \mathrm{gm} / \mathrm{dL}$ to $0.36 \mathrm{gm} / \mathrm{dL}$ when LED power was standardized. The PPG system, which was designed with LED power standardization, has high linearity for hemoglobin estimation with a coefficient of determination $\left(\mathrm{R}^{2}=0.981\right)$ compared to without standardization of LED power (where $\mathrm{R}^{2}=0.965$ ). Also using Bland-Altman, our results showed a bias and SD of $0.15 \pm 0.29 \mathrm{gm} / \mathrm{dL}$ between non-invasive measurement (designed system with standardization of LED power) and invasive measurement (pathology) compared to $0.47 \pm 0.38 \mathrm{gm} / \mathrm{dL}$ without standardization of LED power. Also, it shows less bias and SD which indicates less spread of readings with standardization of LED power compared to without standardization of LED power.

\section{REFERENCES}

[1] J. Kraitl, H. Ewald, and H. Gehring, “An optical device to measure blood components by a photoplethysmographic method,” Journal of Optics A: Pure and Applied Optics, vol. 7, no. 6, pp. S318-S324, 2005, doi: 10.1088/1464-4258/7/6/010.

[2] Y. Balarajan, U. Ramakrishnan, E. Ozaltin, A. H. Shankar, and S. V. Subramanian, "Anaemia in low-income and middle-income countries," The Lancet, vol. 378, no. 9809, pp. 2123-2135, 2011, doi: 10.1016/S0140-6736(10)62304-5.

[3] G. A. Stevens et al., "Global, regional, and national trends in haemoglobin concentration and prevalence of total and severe anaemia in children and pregnant and non-pregnant women for 1995-2011: a systematic analysis of population representative data," Lancet Global Health, vol. 1, no. 1, pp. e16-e25, 2013, doi: 10.1016/S2214-109X(13)70001-9.

[4] B. N. Jadhav, "A critical review on iron deficiency anaemia in female population of developing India," International Journal Fauna Biological Studies, vol. 3, no. 5, pp. 116-119, 2016.

[5] E. McLean, I. Egli, M. Cogswell, B. Benoist, and D. Wojdyla, "Worldwide prevalence of anemia in preschool aged children, pregnant women and non-pregnant women of reproductive age," Nutritional anemia, pp. 1-12, 2007. 
[6] A. S. Ahankari, A. W. Fogarty, L. J. Tata, J. V. Dixit, and P. R. Myles, “Assessment of a non-invasive haemoglobin sensor NBM 200 among pregnant women in rural India," BMJ Innovations, vol. 2, no. 2, pp. 70-77, 2016, doi: 10.1136/bmjinnov-2015-000085.

[7] C. Massot and J. Vanderpas, "A survey of iron deficiency anaemia during pregnancy in Belgium: analysis of routine hospital laboratory data in Mons," Acta Clinica Belgica, vol. 58, pp. 169-177, 2003, doi: 10.1179/acb.2003.58.3.004.

[8] S. Acharya et al., "Non-invasive estimation of hemoglobin using a multi-model stacking regressor," IEEE Journal of Biomedical and Health Informatics, vol. 24, no. 6, pp. 1717-1726, 2020, doi: 10.1109/JBHI.2019.2954553.

[9] S. T. Bateman et al., "Anemia, blood loss, and blood transfusions in North American children in the intensive care unit," American Journal of Respiratory and Critical Care Medicine, vol. 178, no. 1, pp. 26-33, 2008, doi: 10.1164/rccm.200711-1637OC.

[10] D. Rout, S. Sachdev, and N. Marwaha, "Evaluation of new non-invasive and conventional invasive methods of haemoglobin estimation in blood donors," Indian Journal of Medical Research, vol. 149, no. 6, pp. 755-762, 2019, doi: 10.4103/ijmr.IJMR_301_17.

[11] E. Bridges and J. J. Hatzfeld, "Noninvasive continuous hemoglobin monitoring in combat casualties: a pilot study," Shock, vol. 46, no. 3, pp. 55-60, 2016, doi: 10.1097/SHK.0000000000000654.

[12] G. Avcioglu, C. Nural, F. M. Yilmaz, P. Baran, Ö. Erel, and G. Yilmaz, "Comparison of noninvasive and invasive point-of-care testing methods with reference method for hemoglobin measurement," Journal of Clinical Laboratory Analysis, vol. 32, no. 3, pp. 1-7, 2018, doi: 10.1002/jcla.22309.

[13] U. Timm, E. Lewis, G. Leen, D. McGrath, J. Kraitl, and H. Ewald, "Non-invasive continuous online hemoglobin monitoring system," Sensors Applications Symposium, 2010, pp. 131-134, doi: 10.1109/SAS.2010.5439415.

[14] R. Doshi and A. Panditrao, "Non-invasive optical sensor for hemoglobin determination," International Journal of Engineering Research and Applications, vol. 3, no. 2, pp. 559-562, 2013.

[15] M. Azarnoosh and H. Doostdar, "Assessment of photoplethysmography method in extraction of hemoglobin concentration," Journal of Biomedical Physics and Engineering, vol. 9, no. 6, pp. 711-718, 2019, doi: 10.31661/jbpe.v0i0.400.

[16] C. Pinto, J. Parab, and G. Naik, "Non-invasive hemoglobin measurement using embedded platform," Sensing and Biosensing, vol. 29, 2020, doi: 10.1016/j.sbsr.2020.100370.

[17] X. Yi, G. Li, and L. Lin, "Noninvasive hemoglobin measurement using dynamic spectrum," Review of Scientific Instruments, vol. 88 , no. 8, 2017, doi: 10.1063/1.4998978.

[18] "Continuous SpHb provides real-time visibility to changes, or lack of changeshemoglobin between invasive blood samples," Masimo, 2015. [Online]. Available: http://www.masimo.com/technology/co-oximetry/sphb (Acessed on $2^{\text {nd }}$ December 2020).

[19] “The NBM 200 system." Orsense.com. 2018. http://www.orsense.com/product.php?ID=49 (Accesed December 5" , 2020).

[20] World Health Organization, “Anemia." WHO.int. https://www.who.int/health-topics/anaemia\#tab=tab_1/ (Accessed Dec. 2 ${ }^{\text {nd }}$, 2020).

[21] S. Prahl, “Optical Absorption of Hemoglobin.” OMLC.org. 1999. [Online]. Available: https://omlc.org/spectra/hemoglobin/ (Accessed Dec. $\left.7^{\text {th }}, 2020\right)$.

[22] A. N. Bashkatov, E. A. Genina, V. I. Kochubey, and V. V. Tuchin, "Optical properties of human skin, subcutaneous and mucous tissues in the wavelength range from 400 to $2000 \mathrm{~nm}$," Journal of Physics D: Applied. Physics, vol. 38, pp. 2543-2555, 2005, doi: 10.1142/S1793545811001319.

[23] H. Tian, M. Li, Y. Wang, D. Sheng, J. Liu, and L. Zhang, "Optical wavelength selection for portable hemoglobin determination by near-infrared spectroscopy method," Infrared Physics and Technology, vol. 86, pp. 98-102, 2017, doi: 10.1016/j.infrared.2017.09.004.

[24] G. Yoon, S. J. Kim, and K. J. Jeon, "Robust design of finger probe in non-invasive total haemoglobin monitor," Medical \& Biological Engineering and Computing, vol. 43, no. 1, pp. 121-126, 2005, doi: 10.1007/BF02345132.

[25] J. P. deKock and L. Tarassenko, "In vitro investigation of the factors affecting pulse oximetry," Journal of Biomedical Engineering, vol. 13, no. 1, pp. 61-66, 1991, doi: 10.1016/0141-5425(91)90046-a.

[26] I. Y. Petrova et al., "Optoacoustic technique for continuous, noninvasive measurement of total hemoglobin concentration: an in vivo study," The 26th Annual International Conference of the IEEE Engineering in Medicine and Biology Society, vol. 2004, 2004, pp. 2059-2061, doi: 10.1109/IEMBS.2004.1403605.

[27] D. Castaneda, A. Esparza, M. Ghamari, C. Soltanpur, and H. Nazeran, "A review on wearable photoplethysmography sensors and their potential future applications in health care," International Journal Biosensing and Bioelectronics, vol. 4, no. 4, pp. 195-202, 2018, doi: 10.15406/ijbsbe.2018.04.00125.

[28] J. Nirupa and V. J. Kumar, "Non-invasive measurement of hemoglobin content in blood," International Symposium on Medical Measurements and Applications, 2014, pp. 1-5, doi: 10.1109/MeMeA.2014.6860140.

[29] C. Sharma, S. Kumar, A. Bhargava, and S. R. Chowdhury, "Field programmable gate array based embedded system for non-invasive estimation of hemoglobin in blood using photoplethysmography," International. Journal Smart Sensing Intelligent System, vol. 6, no. 3, pp. 1267-1282, 2013, doi: 10.21307/ijssis-2017-589.

[30] J. M. Bland and D. G. Altman, "Measuring agreement in method comparison studies," Statistical Methods Medical Research, vol. 8, no. 2, pp. 135-160, 1999, doi: 10.1177/096228029900800204.

\section{BIOGRAPHIES OF AUTHORS}

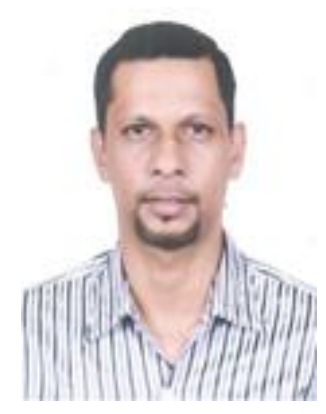

Caje Francis Pinto (D) 8 SC P is an Assistant Professor in the Department of Electronics, St. Xavier's College, Mapusa, Goa. He is having twelve years of teaching experience. He received his B.Sc. (Electronics) and M.Sc. (Electronics) from Goa University in 2003 and 2005 respectively. He is also pursuing a Ph.D. in the Development of Novel Softcore Embedded Architecture for Total Hemoglobin Estimation in the Department of Electronics Goa University, Goa. His areas of interest are Embedded Systems and Biomedical Instrumentation. He has published several papers in national and international level journals and conferences. He can be contacted at email: caj786@gmail.com. 


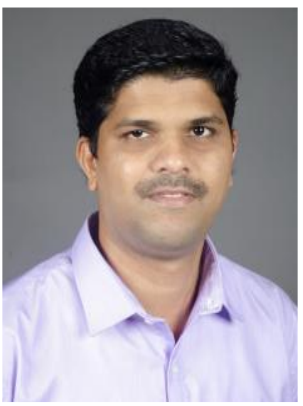

Jivan Shrikrishna Parab (D) $8 \mathrm{SC}$ S $\mathrm{P}$ is an Associate Professor in the Electronics at School of Physical \& Applied Sciences, Goa University, India. He completed his Ph.D. from the same university with the thesis titled "Development of Novel Embedded DSP Architecture for NonInvasive Glucose Analysis." He received his B.Sc. (Electronics) and M.Sc. (Electronics) from Goa University in 2003 and 2005 respectively. He has co-authored four books, three books, published by Springer and the fourth book published by CRC Press. He has published several papers in national and international level journals and conferences. He was also awarded Visvevaraya Young scientist award by MeitY Govt. of India. He can be contacted at email: jsparab@unigoa.ac.in.

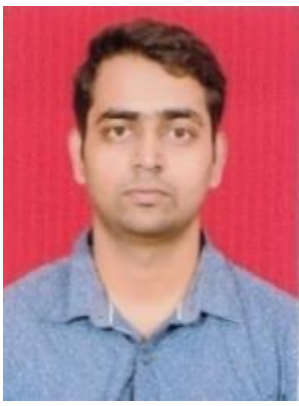

Marlon Darius Sequeira (D) SC S P is an Assistant Professor in the Electronics at School of Physical \& Applied Sciences, Goa University, India. He was a research scholar under the Visvesaraya Ph.D. Scheme. He received his B.Sc. (Electronics) and M.Sc. (Electronics) from Goa University in 2012 and 2014 respectively. He completed his Ph.D. from the same university with the thesis titled "Estimation of Glucose using Fixed Wavelength Light Sources." His research interests include non-invasive estimation of Glucose, Biomedical Instrumentation, digital signal processing, and Embedded systems. He can be contacted at email: marlon@unigoa.ac.in.

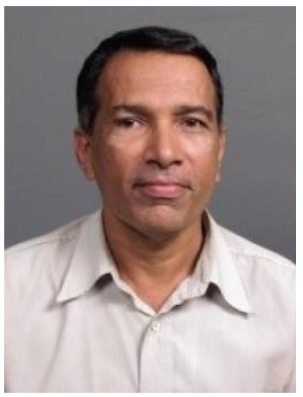

Gourish Naik (DD SC P Former Dean Faculty of Natural Science \& Former Head Department of Electronics) obtained his Ph.D. from the Indian Institute of Science, Bangalore (1987) and served the institute as a research associate in the areas of Optoelectronics and Communication until 1993. For the last 27 years, he has been associated with the Goa University Electronics Program. He has to his credit around 60 odd research papers published in international journals and has presented research works at various national and international forums. He has also authored five books on embedded systems and allied areas published by CRC Press, and Springer, Lambert. He can be contacted at email: gmnaik@unigoa.ac.in. 